\title{
BMJ Open Acute food insecurity and short-term coping strategies of urban and rural households of Bangladesh during the lockdown period of COVID-19 pandemic of 2020: report of a cross- sectional survey
}

\author{
Subhasish Das (D) , ${ }^{1}$ Md. Golam Rasul, ${ }^{1}$ Md Shabab Hossain, ${ }^{1}$ Ar-Rafi Khan, \\ Md Ashraful Alam, ${ }^{1}$ Tahmeed Ahmed (D) , ${ }^{1}$ John D Clemens ${ }^{2}$
}

To cite: Das $S$, Rasul MG, Hossain MS, et al. Acute food insecurity and short-term coping strategies of urban and rural households of Bangladesh during the lockdown period of COVID-19 pandemic of 2020: report of a crosssectional survey. BMJ Open 2020;10:e043365. doi:10.1136/ bmjopen-2020-043365

- Prepublication history and additional material for this paper is available online. To view these files, please visit the journal online (http://dx.doi.org/10. 1136/bmjopen-2020-043365).

Received 01 August 2020 Revised 16 November 2020 Accepted 27 November 2020

Check for updates

(c) Author(s) (or their employer(s)) 2020. Re-use permitted under CC BY-NC. No commercial re-use. See rights and permissions. Published by BMJ.

${ }^{1}$ Nutrition and Clinical Services Division, icddr,b, Dhaka,

Bangladesh

${ }^{2}$ Infectious Diseases Division, icddr,b, Dhaka, Bangladesh

Correspondence to Dr Tahmeed Ahmed; tahmeed@icddrb.org

\section{ABSTRACT}

Introduction We conducted a cross-sectional survey to assess the extent and to identify the determinants of food insecurity and coping strategies in urban and rural households of Bangladesh during the month-long, COVID-19 lockdown period.

Setting Selected urban and rural areas of Bangladesh. Participants 106 urban and 106 rural households. Outcome variables and method Household food insecurity status and the types of coping strategies were the outcome variables for the analyses. Multinomial logistic regression analyses were done to identify the determinants.

Results We found that around $90 \%$ of the households were suffering from different grades of food insecurity. Severe food insecurity was higher in urban (42\%) than rural (15\%) households. The rural households with mild/moderate food insecurity adopted either financial $(27 \%)$ or both financial and food compromised $(32 \%)$ coping strategies, but $61 \%$ of urban mild/moderate food insecure households applied both forms of coping strategies. Similarly, nearly $90 \%$ of severely food insecure households implemented both types of coping strategies. Living in poorest households was significantly associated ( $p$ value $<0.05$ ) with mild/moderate (regression coefficient, $\beta: 15.13,95 \% \mathrm{Cl} 14.43$ to 15.82 ), and severe food insecurity ( $\beta$ : $16.28,95 \% \mathrm{Cl} 15.58$ to 16.97$)$. The statistically significant $(p<0.05)$ determinants of both food compromised and financial coping strategies were living in urban areas $(\beta: 1.8,95 \% \mathrm{Cl} 0.44$ to 3.09$)$, living in poorest ( $\beta$ : $2.7,95 \% \mathrm{Cl} 1$ to 4.45$)$, poorer $(\beta: 2.6,95 \% \mathrm{Cl}$ 0.75 to 4.4$)$ and even in the richer $(\beta: 1.6,95 \% \mathrm{Cl} 0.2$ to $2.9)$ households and age of the respondent $(\beta: 0.1,95 \% \mathrm{Cl}$ 0.02 to 0.21 ).

Conclusion Both urban and rural households suffered from moderate to severe food insecurity during the monthlong lockdown period in Bangladesh. But, poorest, poorer and even the richer households adopted different coping strategies that might result in long-term economic and nutritional consequences.
Strengths and limitations of this study

- This is one of the first surveys that report the food insecurity and related coping strategies of both urban and rural poor households of Bangladesh during the ongoing COVID-19 pandemic.

- The possibility of recall bias might be very low as data were collected through a rapidly done crosssectional survey just at the end of the first month of lockdown.

- Data were collected from only two places and the places were chosen for convenience. A larger sample size involving a wider geographical location would be better for generalisabiity and strength of the study.

- It was not possible to collect the pre-COVID food insecurity status data of the surveyed households and that definitely limits the scope of comparison.

\section{INTRODUCTION}

The severe acute respiratory syndrome COVID-19 was first reported in Wuhan, Hubei Province, China in December 2019. Since then it has rapidly spread all over the world and has caused a large global outbreak and eventually became a major public health concern. ${ }^{2}$ It was later declared as a global pandemic on 11 March 2020 by the WHO, and has resulted in 53507282 confirmed cases worldwide and killed more than 1305164 people around the world as of 15 November $2020 .^{3}$ The rapid transmission and prolonged incubation period make the containment of COVID-19 extremely difficult. ${ }^{4}$ Hence, many countries around the world, including Bangladesh, have had to take the 'lockdown' approach to contain the spread of the virus. During this lockdown most people, apart 
from those involved in emergency services, were directed strictly to remain inside their homes. As a result, the means to earn their daily livings were cut in most cases. The closure of open-air food markets and small food shops added more complexities to the overall situation. Due to the closure of or restrictions on public transport, the food supply chain was also interrupted. The overall situation made people more vulnerable to a state of acute food insecurity due to a sudden drop in supply or access to food. The World Food Summit in 1996 determined that food security exists when all people, at all times, have physical and economic access to sufficient, safe and nutritious food to meet their dietary needs and food preferences for an active and healthy life. ${ }^{5}$ Food insecure households lack access to adequate food because of limited money or other resources, and this is a leading health and nutrition issue during any epidemic. ${ }^{6}$ In Britain, after a 3-week long lockdown during the COVID-19 outbreak, about $16.2 \%$ of the surveyed adults experienced food insecurity and an additional $21.6 \%$ of the adults felt worried about availing the desired food. ${ }^{7}$ The study also reported that the percentage of adults experiencing food insecurity was four times higher than that prior to the pandemic.

The COVID-19 pandemic has caused havoc in more than 200 countries and territories and has the potential to result in acute food insecurity and undernutrition among the poor people residing in the low/middleincome countries (LMICs) with poor capital resources, such as Bangladesh. The hypothesis is based on two issues-structural and shocks and stressors. ${ }^{8-10}$ In LMICs, food and agroindustry typically face difficulties due to inadequate infrastructures. ${ }^{8}$ On top of such structural deficiencies, when shocks and stressors such as drought, flood or any epidemics occur, those events severely affect different attributes or components of food supply chains. As a result most of them fail to operate efficiently and the outcome is food insecurity. ${ }^{11}$ Though such food insecurity is expected to hit the poorest most, depending on the unavailability of supports, even the lower-middle income and middle income groups might become equally vulnerable. Household food insecurity is a risk factor for malnutrition among all age groups and the impact extends from undernutrition to overweight/obesity and hidden hunger. ${ }^{12-14}$ Moreover, food insecurity, even for a brief period, can result in long-term developmental, psychological, physical and emotional harm to the children living in low-income households. ${ }^{15}$

Acute food insecurity that occurs during disasters is known to account for one-tenth of the overall global prevalence of food insecurity. ${ }^{14}$ When the households are hit by different domains of food insecurity (anxiety and uncertainty about the household food supply, inadequate quality and insufficient quantity of food intake), they plan strategically and consider a range of coping strategies to live and to thrive. ${ }^{16}{ }^{17}$ The coping strategies extend from a compromise in the quality and quantity of food consumption to mortgage of assets or borrowing money. ${ }^{18}$ According to the reports published by Corbett, during recurrent famines in the 1970s and 1980s, African households changed their cropping and planting practices, took loans from merchants, migrated to other areas, rationed foods and sold their household assets. ${ }^{19}$ Hoddinott used longitudinal data from rural Zimbabwe to discuss the impact of shocks from the context of asset holdings. He found that during the 1994-1995 drought, households sold their livestock, particularly oxen and cows. ${ }^{19}$ Devereux divided the household responses during the events of such food shortages in two categories related to food consumption behaviour-protect consumption and modify consumption. ${ }^{20}$ To protect food consumption the surveyed households either purchased grains by selling non-food crops and assets (eg, animals), borrowing cash, postponing debt repayment, reducing non-food spending, begging or gathering food aids. They also modified their consumption practice by taking smaller portions, fewer meals per day, taking less preferred varieties or less nutritious diets. ${ }^{20}$ When the food insecure households adopt different coping strategies, they often also convert to a new livelihood pattern that might make them more vulnerable to undernutrition. ${ }^{21}$ Hence, understanding the food insecurity status and related coping strategies is critical for formulating appropriate policy and designing effective programmes to mitigate the food insecurity and to avert the nutritional consequences related to COVID-19 and similar epidemics and pandemics.

We therefore assessed the extent and identified the determinants of food insecurity and short-term coping strategies adopted by households in one urban and one rural area in Bangladesh after a month-long lockdown for the ongoing COVID-19 pandemic.

\section{METHODOLOGY}

\section{Setting, study design and sample size}

We conducted the cross-sectional survey in both urban (Bauniabadh slum area in Mirpur, Dhaka) and rural (Matlab in Chandpur district) areas of Bangladesh. The urban site represents typical congested urban settlements where population density is $>38000$ people $/ \mathrm{km}^{2}$. The family size and sex distribution were comparable to national data and most of the people are day labourers, garment workers and transport workers. The details of the urban site can be found here. ${ }^{22}$ Matlab, the rural site, is located about $55 \mathrm{~km}$ southeast of Dhaka where the main occupations of men are agriculture, fishery and trade. ${ }^{23}$ The participants of the study presented here were originally recruited in a study named 'Sunlight, Dietary Habits and Vitamin D status in Infants: A cross-sectional study in an urban and a rural area of Bangladesh (Vit-D study)' where 12-24 months old children without severe acute malnutrition, severe anaemia (serum haemoglobin level $<8 \mathrm{~g} / \mathrm{dL}$ ) or any congenital anomalies living in urban and rural areas of Bangladesh were recruited. Initially, trained field workers visited the households and listed the eligible participants to a sampling frame. Then, 240 households 
with children of above-mentioned criteria were randomly selected from the sampling frame using computergenerated random sampling numbers. As a part of the 'Vit-D' study, dietary intake data of the infants were being collected from 240 households (120 rural and 120 urban) and we took this opportunity to document data on household food insecurity and related coping strategies from the mothers/caregivers of the children after a monthlong lockdown period due to COVID-19 pandemic. For calculating the sample size, we initially assumed that $50 \%$ of the households might be suffering from severe food insecurity due to the lockdown. Considering this assumption and at a chance of $5 \%$ type- 1 error, the required minimum sample size was 96 at $10 \%$ absolute error or precision. We interviewed 212 households (106 urban and 106 rural) from the 240 households mentioned above over telephone. We could not communicate to the rest of the households over telephone. The respondents of the interviews were the homemakers who were the mothers of the children recruited in the Vit-D study.

\section{Data, indicators and outcome variables}

The government of Bangladesh imposed a nationwide restriction on movement during the lockdown from 26 March 2020. We started data collection from 26 April 2020 and collected data of previous 4 weeks on household level food insecurity from 212 female adults over telephone using the Household Food Insecurity Access Scale (HFIAS) guideline version 3, developed by Food and Nutrition Technical Assistance, USAID. ${ }^{24}$ The HFIAS documents the experience of food insecurity based on lack of access due to poverty rather than shortage of supply and captures the predictable reactions and responses and summarises it in a scale. ${ }^{24}$ The scale calculates household food insecurity using nine questions (see online supplemental file 1)-worry about food, unable to eat preferred foods, eat just a few kinds of foods, eat foods they really do not want to eat, eat a smaller meal, eat fewer meals in a day, no food of any kind in the household, go to sleep hungry, go a whole day and night without eating to assess the level of anxiety and uncertainty of the participants about household food supply, insufficient quality of food and insufficient food intake. ${ }^{24}$ If the responses to any of the questions were 'yes', we then recorded and categorised the frequency of occurrence of that experience as rarely (once or twice), sometimes (three to ten times) and often (more than ten times) in the past 4 weeks. Each response was then scored on a range of $0-3$; where 0 stands for 'no occurrence' and 3 for 'often'. An HFIA category variable was then calculated and assigned for each of the households by coding them for the food insecurity (access) categories. The data analyst coded frequency of occurrence as 0 when the response to all the questions were 'no'. Similarly, other categories of food insecurity were assigned to the households sequentially (see online supplemental file 1 ). Based on the frequency of that response the Household Food Insecurity Access Prevalence on the level of access to food as food secure, mildly food insecure, moderately food insecure and severely food insecure households were calculated. The details of the calculation can be found in the HFIAS indicator guide. ${ }^{24}$ We merged mildly and moderately food insecure households into one category for this specific analysis and thus, there were three types of households in the final data set: food secure; mildly to moderately food insecure and severely food insecure households. The nine indicators were also categorised into three Household Food Insecurity Access-related domains to capture the households' experience on-anxiety and uncertainty about the household food supply, inadequate quality of food, and insufficient food intake. ${ }^{24}$ The short-term coping strategies adopted by the food insecure households were categorised into three groups-financial coping (sale or credit of assets, borrowing money and food), food compromise coping (compromising quality and quantity of food) and both financial and food compromise coping strategies. Both the food insecurity status and the coping strategies were the outcome variables for the analyses.

\section{Data analysis}

We first described the overall and food insecurity specific socioeconomic and household characteristics using mean, $\mathrm{SD}$, frequency and percentages. One-way analysis of variance was performed for group wise comparison of quantitative symmetric variables. Groupwise comparison of the quantitative asymmetric variables was done using the Kruskal-Wallis test. $\chi^{2}$ test or Fisher's exact test was used for qualitative variables. We followed the 'Household Food Insecurity Access Scale (HFIAS) for Measurement of Food Access: Indicator Guide VERSION 3' for measuring the indicators of household food insecurity. ${ }^{24}$ For presenting the economic condition of the households, we calculated a Household Asset Index using household asset data obtained from the socioeconomic status questionnaire. The index was calculated based on household's ownership of selected assets (household's ownership of electric iron, chair, table, sofa, computer, television, refrigerator and motorcycle), number of rooms in the house, monthly income of the family and ownership of a bank account. From the asset-related dichotomous variables (having or not having an asset), using principal components analysis, we produced a common factor score for each household. We divided first principal component score into quintiles to create five categories where first category (bottom 20\%) represents poorest and fifth category (top $20 \%$ ) represents richest households. Multinomial logistic regression analyses were done to measure the association of the outcome variables to different predictor variables. Initially bivariate regression models were fitted and the variables that had a $p$-value less than 0.05 were considered for fitting the multivariate multinomial logistic regression models. In the multinomial logistic regression models, regression coefficients with $95 \%$ CIs were generated and reported. Data analysis was done in R (V.3.6.2) and 'nnet' package was employed. ${ }^{26}$ 
Table 1 Household Food Insecurity Access Prevalence and sociodemographic characteristics of respondents

\begin{tabular}{|c|c|c|c|c|c|c|}
\hline & All $(n=212)$ & $\begin{array}{l}\text { Food secure } \\
(n=24)\end{array}$ & $\begin{array}{l}\text { Mild-to- } \\
\text { moderate food } \\
\text { insecure }(n=128)\end{array}$ & $\begin{array}{l}\text { Severely food } \\
\text { insecure }(n=60)\end{array}$ & $\begin{array}{l}P \\
\text { value }\end{array}$ \\
\hline & & \multicolumn{5}{|l|}{ n (\%) } \\
\hline Household head's sex & Male & $158(74.5)$ & $17(70.8)$ & $93(72.7)$ & $48(80)$ & 0.508 \\
\hline \multirow{6}{*}{$\begin{array}{l}\text { Occupation of } \\
\text { household head }\end{array}$} & Not currently working & $20(9.4)$ & $3(12.5)$ & $14(10.9)$ & $3(5)$ & \multirow[t]{6}{*}{0.085} \\
\hline & Fishing/agricultural worker & $6(2.8)$ & $0(0)$ & $6(4.7)$ & $0(0)$ & \\
\hline & Day labourer & $51(24.1)$ & $3(12.5)$ & $26(20.3)$ & $22(36.7)$ & \\
\hline & Businessman & $56(26.4)$ & $8(33.3)$ & $32(25)$ & $16(26.7)$ & \\
\hline & Professional wage earner & $22(10.4)$ & $1(4.2)$ & $13(10.2)$ & $8(13.3)$ & \\
\hline & Others & $57(26.9)$ & $9(37.5)$ & 37 (28.9) & $11(18.3)$ & \\
\hline Mother/housewife earns & Yes & $19(9)$ & $0(0)$ & $14(10.9)$ & $5(8.3)$ & 0.251 \\
\hline $\begin{array}{l}\text { Households owns } \\
\text { chicken or ducks }\end{array}$ & Yes & $53(25)$ & $10(41.7)$ & 35 (27.3) & $8(13.3)$ & 0.016 \\
\hline $\begin{array}{l}\text { Any member of the } \\
\text { household have a bank } \\
\text { account }\end{array}$ & Yes & $84(39.6)$ & $17(70.8)$ & $54(42.2)$ & $13(21.7)$ & $<0.001$ \\
\hline $\begin{array}{l}\text { Any member of the } \\
\text { household own any } \\
\text { agricultural land }\end{array}$ & Yes & $25(11.8)$ & $5(20.8)$ & $18(14.1)$ & $2(3.3)$ & 0.018 \\
\hline \multirow[t]{6}{*}{ Asset Index } & First quintile (poorest) & $51(24.1)$ & $0(0)$ & $32(25)$ & $19(31.7)$ & \multirow[t]{5}{*}{$<0.001$} \\
\hline & Second quintile (poorer) & $37(17.5)$ & $2(8.3)$ & $18(14.1)$ & $17(28.3)$ & \\
\hline & Third quintile (middle) & $41(19.3)$ & $2(8.3)$ & $29(22.7)$ & $10(16.7)$ & \\
\hline & Fourth quintile (richer) & $41(19.3)$ & $7(29.2)$ & 25 (19.5) & $9(15)$ & \\
\hline & Fifth quintile (richest) & $42(19.8)$ & $13(54.2)$ & 24 (18.8) & $5(8.3)$ & \\
\hline & & Mean (SD) & & & & \\
\hline \multicolumn{2}{|c|}{ Years of education of household head } & $5.41(4.19)$ & $8.08(4.41)$ & $5.01(4.13)$ & $5.18(3.92)$ & $<0.01$ \\
\hline \multicolumn{2}{|l|}{ People per room } & $2.67(1.25)$ & $1.93(0.83)$ & $2.52(1.18)$ & $3.29(1.28)$ & $<0.001$ \\
\hline \multicolumn{2}{|l|}{ Respondent's age (in years) } & $26.1(5.06)$ & $24.6(5.41)$ & $25.8(4.91)$ & $27.3(5.06)$ & 0.05 \\
\hline \multicolumn{2}{|c|}{ Respondent's age at first marriage (in years) } & $17.4(2.76)$ & $17.4(2.76)$ & $17.5(2.73)$ & $17.3(2.87)$ & 0.95 \\
\hline \multicolumn{2}{|c|}{ Years of education of the respondent (in years) } & $6.86(3.88)$ & $9.67(2.96)$ & $6.87(3.69)$ & $5.72(4.08)$ & $<0.001$ \\
\hline \multicolumn{2}{|c|}{ Monthly family income (in US\$) } & $252(351)$ & $550(921)$ & $228(154)$ & $185(129)$ & $<0.001$ \\
\hline
\end{tabular}

\section{Patient and public involvement statement}

Patients or the public were not involved in the design, or conduct, or reporting, or dissemination plans of our research.

\section{RESULTS}

The descriptive characteristics of the households are presented in table 1 . Men were the household heads in majority of the families, most of them being day labourers and small business holders, and nearly half of them with no formal education. Seventy per cent of the food secure households consisted of at least one member having a bank account, but the percentage came down to $42 \%$ for mild/moderate food insecure households and just $22 \%$ for severely food insecure households. Most of the households had a low socioeconomic status with an average income of US\$252 (SD 351) per month. The monthly family income of food secure households was nearly double (US $\$ 550$ vs US $\$ 228$, p value $<0.001$ ) and triple (US $\$ 550$ vs US $\$ 185, \mathrm{p}<0.001$ ) than the mild/moderate and severe food insecure households, respectively. Most of the food insecure households were in the lower quintiles of the Asset Index. Both mild/moderate and severe food insecure households had more crowded living environments than the food secure households $(p<0.001)$. Heads of the food secure households had more years of education than the rest. Overall, food secure households had significantly $(\mathrm{p}<0.05)$ better statistics regarding ownership of assets, household income, household level crowding and education status compared to the food insecure households.

We found that around 90\% of the households we surveyed were suffering from some form of food insecurity. The prevalence of severe food insecurity was 
Table 2 Frequency of occurrence of nine conditions of Household Food Insecurity Access Scale (HFIAS), Prevalence of Household Food Insecurity Domains and Household Food Insecurity Access Prevalence (HFIAP) statistics

(i) Frequency of occurrence of nine conditions of Household Food Insecurity Access Scale (HFIAS) (n, (\%))

\begin{tabular}{|c|c|c|c|c|c|}
\hline Domains & HFIAS conditions & Never & $\begin{array}{l}\text { Rarely (once or } \\
\text { twice) }\end{array}$ & $\begin{array}{l}\text { Sometimes } \\
\text { (3-10 times) }\end{array}$ & $\begin{array}{l}\text { Often (>10 } \\
\text { times) }\end{array}$ \\
\hline $\begin{array}{l}\text { Anxiety and } \\
\text { uncertainty about } \\
\text { the household } \\
\text { food supply }\end{array}$ & $\begin{array}{l}\text { Worried that household would not have enough } \\
\text { food }\end{array}$ & 35 (16.5) & $12(5.7)$ & $29(13.7)$ & $136(64.1)$ \\
\hline \multirow[t]{3}{*}{$\begin{array}{l}\text { Inadequate } \\
\text { quality of food }\end{array}$} & $\begin{array}{l}\text { Any household members were not able to eat } \\
\text { the kinds of foods they preferred because of a } \\
\text { lack of resources }\end{array}$ & 70 (33) & $19(9)$ & 37 (17.4) & $86(40.6)$ \\
\hline & $\begin{array}{l}\text { Any household members had to eat a limited } \\
\text { variety of foods due to a lack of resources }\end{array}$ & $39(18.4)$ & $17(8)$ & 37 (17.4) & $119(56.1)$ \\
\hline & $\begin{array}{l}\text { Any household member had to eat some foods } \\
\text { that they really did not want to eat because of } \\
\text { a lack of resources to obtain other types of food }\end{array}$ & $75(35.4)$ & $20(9.4)$ & 27 (12.7) & $90(42.45)$ \\
\hline \multirow{4}{*}{$\begin{array}{l}\text { Insufficient food } \\
\text { intake }\end{array}$} & $\begin{array}{l}\text { Any household member had to eat fewer meals } \\
\text { in a day because there was not enough food }\end{array}$ & $188(86.7)$ & $18(8.5)$ & $6(2.8)$ & $0(0)$ \\
\hline & $\begin{array}{l}\text { Was there ever no food to eat of any kind in the } \\
\text { household because of a lack of resources to } \\
\text { get food }\end{array}$ & 189 (89.15) & $20(9.4)$ & $1(0.5)$ & $2(0.9)$ \\
\hline & $\begin{array}{l}\text { Any household member went to sleep at night } \\
\text { hungry because there was not enough food? }\end{array}$ & $192(90.6)$ & $13(6.13)$ & $6(2.8)$ & $1(0.5)$ \\
\hline & $\begin{array}{l}\text { Any household member went a whole day and } \\
\text { night without eating anything because there } \\
\text { was not enough food }\end{array}$ & 211 (99.5) & $1(0.5)$ & $0(0)$ & $0(0)$ \\
\hline
\end{tabular}

\begin{tabular}{llll}
$\begin{array}{l}\text { (ii) Household Food Insecurity Access-related Domains (Yes to at least } \\
\text { one condition of a domain (n, (\%)) }\end{array}$ & Urban & Rural & Combined \\
\hline Anxiety and uncertainty about the household food supply & $95(89.6)$ & $82(77.3)$ & $177(83.5)$ \\
\hline Inadequate quality & $98(92.4)$ & $77(72.6)$ & $175(82.5)$ \\
\hline Insufficient quantity of food intake & $67(63.2)$ & $34(32.1)$ & $101(47.6)$ \\
\hline (iii) Household Food Insecurity Access Prevalence (HFIAP) (n, (\%)) & Urban & Rural & Combined \\
\hline Severely food insecure households & $44(41.5)$ & $16(15.1)$ & $60(28.3)$ \\
\hline Mild to moderately food insecure households & $54(50.9)$ & $74(69.8)$ & $128(60.4)$ \\
\hline Food secure households & $8(7.6)$ & $16(15.1)$ & $24(11.3)$ \\
\hline
\end{tabular}

significantly higher $(\mathrm{p}<0.05)$ in urban households $(42 \%)$ than their rural $(15 \%)$ counterparts. On the other hand, in the rural area, $70 \%$ households had mild to moderate food insecurity while in the urban area the prevalence was $50 \%$ (table 2). Table 2 also shows the findings of the nine conditions of HFIAS and its three domains-anxiety and uncertainty about the household food supply, inadequate quality of food and insufficient quantity of food. We have found that more than $85 \%$ households had anxiety regarding the food supply, $90 \%$ took food of inadequate quality and $60 \%$ of them took insufficient quantity of food. The scenario was worse in urban areas than in rural areas.
Figure 1 presents the coping strategies adopted by the urban and rural households to combat the food insecurity during the lockdown period. Most of the urban households either borrowed money or food or consumed fewer items of food or changed food habits. The scenario is similar in the rural households. About one-third of the rural households adopted both financial and food compromisation-related coping strategies. This scenario was however much critical for the urban households as nearly $71 \%$ of them had to adopt both types of coping strategies (figure 2). Interestingly, a total of 42 (20\%) households did not adopt any coping strategies at all. Out of these 42 households, 19 were food secure, 13 were mildly and 10 were moderately food insecure households. 


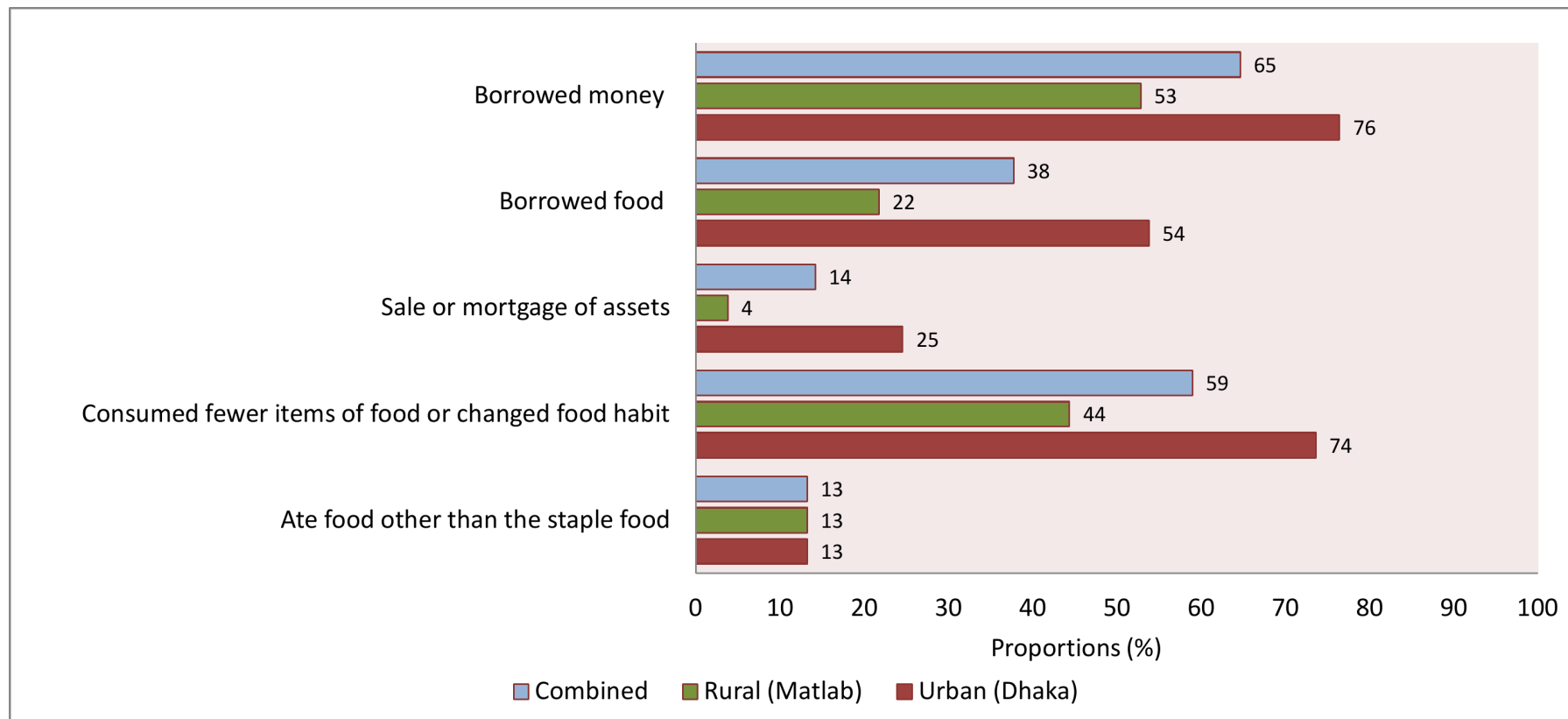

Figure 1 Proportions of different coping strategies adopted by the urban and rural households (multiple responses were counted).

That means, nearly $48 \%$ of mildly food insecure and $10 \%$ of moderately food insecure households did not adopt any coping strategies. And only a few of those households (28 of 212 households) received any help from the government or non-government organisations or any relatives during the lockdown period. That means, they just did not take any strategy and remained food insecure.

Figure 3 presents the proportions of different types of coping strategies adopted by urban and rural household stratified by different categories of food insecurity status. Households with mild-to-moderate food insecurity adopted all types of coping strategies. However, nearly $90 \%$ of severely food insecure households implemented both types of coping strategies to combat the acute food insecurity due to COVID-19 lockdown.

Tables 3 and 4 illustrate the determinants of household food insecurity and coping strategies. We have found that living in poorest households was significantly associated $(p<0.05)$ to mild/moderate (regression coefficient, $\beta$ : $15.13,95 \%$ CI 14.43 to 15.82 ), and severe food insecurity ( $\beta$ : $16.28,95 \%$ CI 15.58 to 16.97 ). The statistically significant $(p<0.05)$ determinants of both food compromised and financial coping strategies that we found were living in urban areas $(\beta: 1.8,95 \% \mathrm{CI} 0.44$ to 3.09$)$, in poorest ( $\beta: 2.7,95 \%$ CI 1 to 4.45$)$, poorer $(\beta: 2.6,95 \%$ CI 0.75 to 4.4$)$ and even in the richer ( $\beta: 1.6,95 \%$ CI 0.2 to 2.9$)$

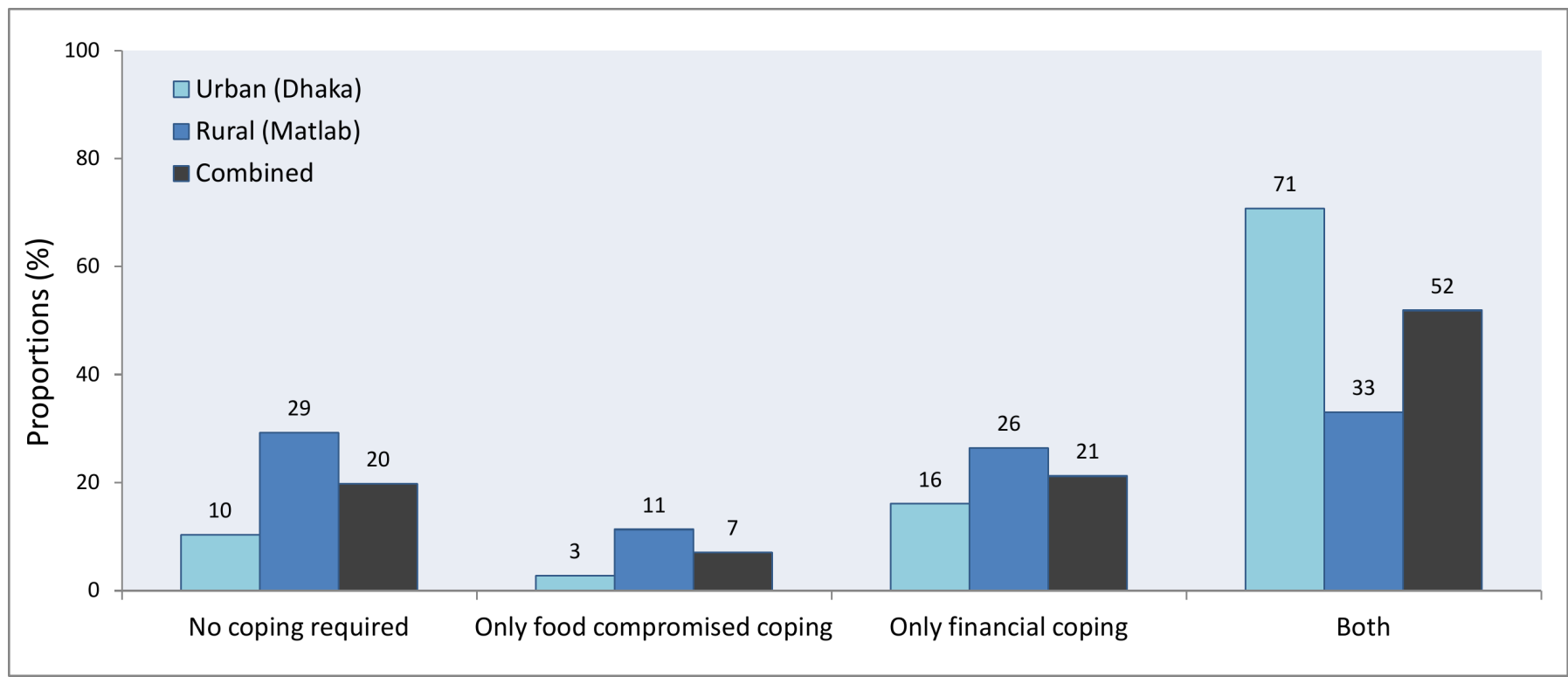

Figure 2 Proportions of different categories of coping strategies adopted by urban and rural households. 


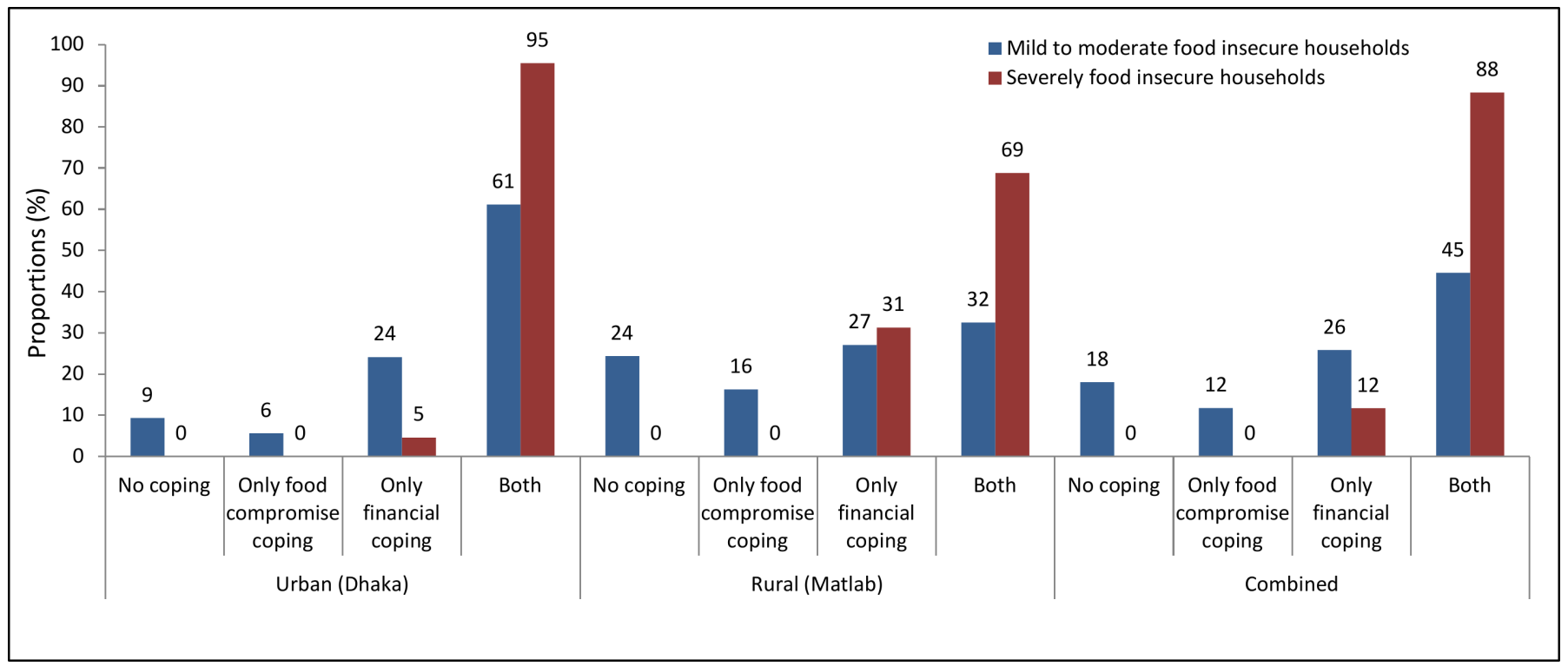

Figure 3 Proportions of different types of coping strategies adopted by urban and rural household stratified by different categories of food insecurity status.

households and age of the respondent $(\beta: 0.1,95 \% \mathrm{CI}$ 0.02 to 0.21$)$.

\section{DISCUSSION}

The emergence of COVID-19 pandemic has not only affected the health of billions of people around the world, it has also introduced food insecurity to their households. Our study reports that $90 \%$ of the households we surveyed were suffering from food insecurity during the lockdown period. It was not possible to associate the level of food insecurity we observed with the occurrence of the pandemic, as we did not have any appropriate control group for comprison. But, a small body of literature is already available to support our findings. The results of surveys conducted in Kenya, Nigeria, Mozambique and Rwanda in early/mid-April 2020 corroborate our findings as, across these countries, $79 \%-87 \%$ of respondents were worried about lack of sufficient food within the last 7 days of reporting due to the COVID-19 pandemicrelated control measures. ${ }^{27}$ Lancet Global Health recently published a paper that also reported that nearly $70 \%$ of the rural households of Bangladesh were suffering from some forms of food insecurity during COVID-19 lockdown. ${ }^{28}$ The study surveyed 2420 households and found that before the pandemic only $136(5 \cdot 6 \%)$ of 2420 and 65 $(2.7 \%)$ of 2420 families experienced moderate and severe food insecurity, respectively. But during the lockdown the tally of households experiencing any level of the food insecurity increased by $51.7 \%$ and the proportions of mild, moderate and severe food insecurity increased by $18 \%$, $36 \%$ and $15 \%$, respectively. ${ }^{28}$ Though this is not possible to make rigorous comparison with the pre-COVID studies, but, from the literatures published in the pre-COVID years we can see that the prevalence of food insecurity in Bangladeshi households during the lockdown period that we reported here is much higher than the pre-COVID time. A study done in 2018 using a nationwide survey data found that $56.5 \%$ households were either mildly, moderately or severely food insecure. ${ }^{29}$ Another study reported that, according to Bangladesh Demographic and Health Survey 2011 data, 36\% households were food insecure. ${ }^{30}$ The prevalence of different domains of food insecurityanxiety and uncertainty about food, inadequate quality of food and insufficient quantity of food were also very high than the pre-COVID years. The prevalence was higher than a report on household food insecurity access-related conditions published in 2013 by Ali et al, at least in two domains - anxiety and uncertainty about food and inadequate quality of food. ${ }^{11}$ Food systems encompass 'all the elements (environment, people, inputs, processes, infrastructures, institutions, etc.) and activities that relate to the production, processing, distribution, preparation, consumption (and waste management) of food, and the output of these activities, including socioeconomic and environmental outcomes'. ${ }^{31}$ Hence, any physical and economic disruptions of the food supply chain might lead to acute food shortage and price hike in both rural and urban areas and that might implicate in food insecurity. ${ }^{32}$ This is the mechanism that explains such high prevalence of food insecurity during the first month of lockdown that we have reported here.

Our descriptive analysis reports that, during the lockdown period, urban households were suffering from a higher prevalence of food insecurity than the rural households and the scenario was similar in all three domains of food insecurity. But the association between household food insecurity and residential area was not found to be statistictically significant in multivariable analysis. Similar to our finding, a scientific report from Bangladesh that was published in 2017 did not find any 


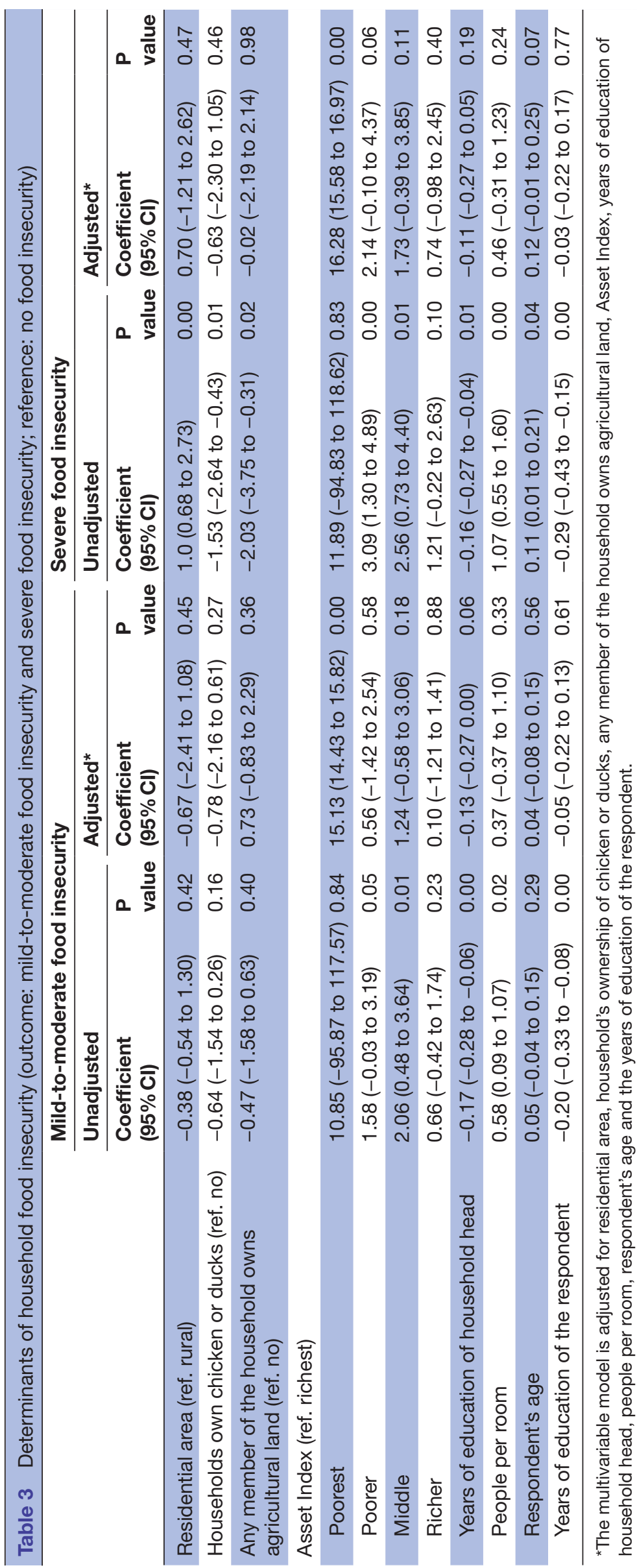




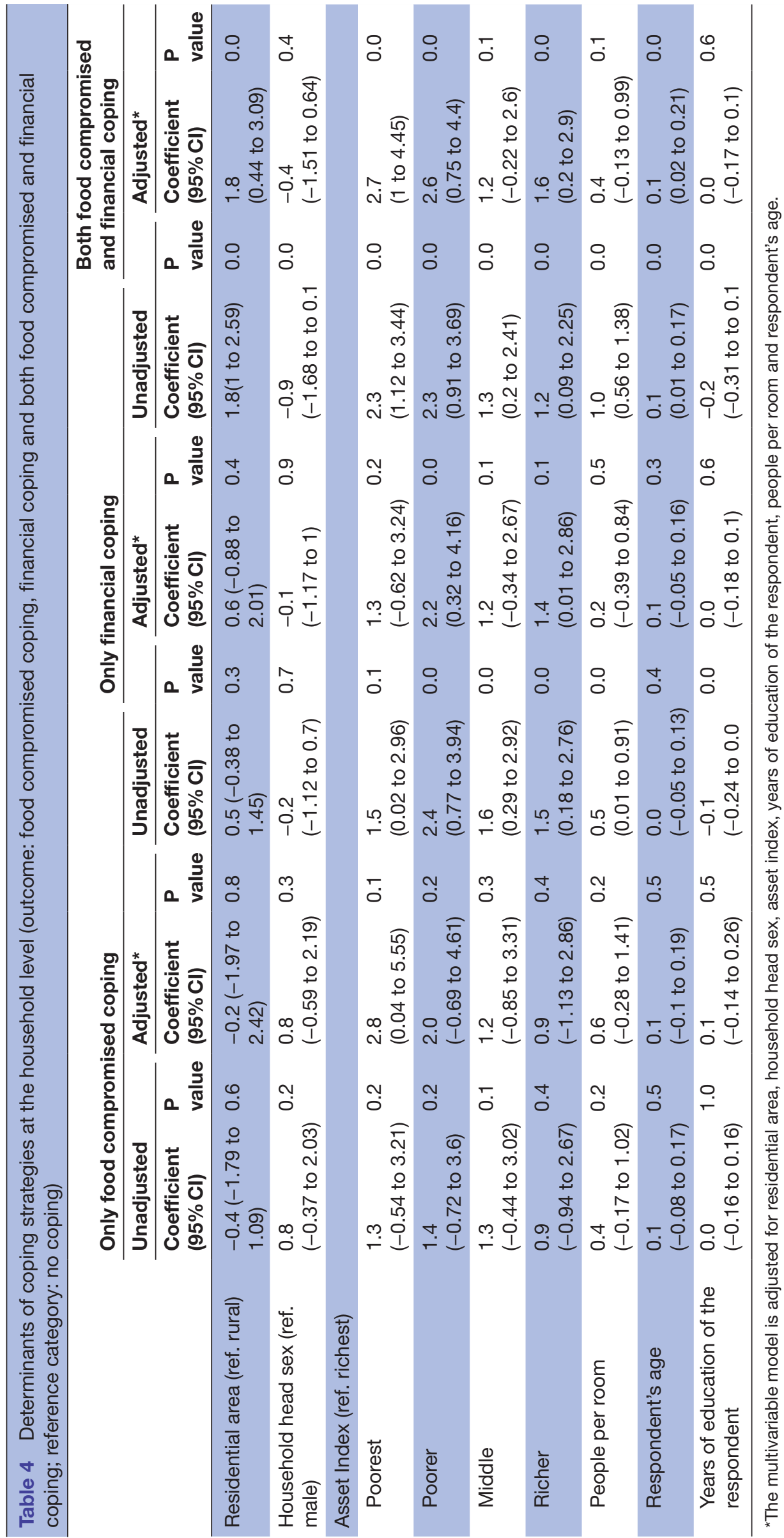


statistically significant role of residential status in household food insecurity. ${ }^{33}$ But we have found that urban households had significantly higher odds of applying both food compromised and financial coping techniques than their rural counterparts. This finding warrants some discussion. A recent situation report by the Food and Agriculture Organization on the impact of COVID-19 on 'Dhaka's food markets and food prices' stated that, as many groceries selling fresh vegetables and meat were closed, the average prices of the food items were reported to be $20 \%$ higher than the prelockdown prices. ${ }^{34}$ Moreover, during the lockdown period, bread earners of the urban poor families, who are mostly day labourers and small business holders, sacrificed their means of earning and stayed home. A recent population-based survey in urban Dhaka on the impact of COVID-19 pandemic on livelihoods reported that a $6 \%$ of the respondents lost their jobs and $30 \%$ experienced a decrease in income. ${ }^{35}$ On the other hand, farmers of rural Bangladesh reported serious difficulties in selling and transporting their products due to higher transport costs and shortages of labourers. As a result, despite a higher retail price in the cities, prices of the products at village markets fell by $17 \%-70 \%$ and the farmers had to accept considerable amount of food wastage which created a financial loss in the agro-based rural economy. ${ }^{36}{ }^{37}$ International Food Policy Research Institute and World Food Programme estimated that, in 2020, an additional 140 million people might be suffering from extreme poverty and the number of people in LMICs facing acute food insecurity will nearly double to 265 million by the end of the year. ${ }^{38}$ In our study we have revealed a similar scenario where the prevalence of food insecurity was very high in both urban and rural households. Though the financial loss might be the factor responsible for this, the root causes behind this might be different. Hence, in addition to ensuring a crisis resilient business model for the poor, establishing a more dynamic food distribution system is a must to combat the widespread food insecurity situation that has arisen during the ongoing pandemic.

From the analysis of coping strategies we found that most of the households borrowed money or food to cope with the situation whereas a good proportion of them also consumed fewer items of food or changed dietary habits. We have also found that the rural households that were mild/moderate food insecure adopted either financial or both financial and food compromised coping strategies, but urban mild/moderate food insecure households mostly applied both forms of coping strategies. The scenario is different in case of severely food insecure households as most of them adopted both forms of coping strategies to survive. In accord with our findings, a nationwide survey report from Bangladesh stated that coping strategies adopted by the food insecure households consisted of a mixed approach during food insecurity and more exorbitant strategies were adopted when food insecurity condition worsened. ${ }^{33}$ Households that used financial coping by borrowing food or money might have built up debts, with the result that in the near future they might have to repurpose the food costs to pay that debt. Moreover, the children and women of the households that compromised the quality and quantity of foods might suffer from different forms acute undernutrition due to lack of dietary diversity, to be followed by micronutrient deficiency and hidden hunger if they continue to suffer from food insecurity. ${ }^{39-41}$ The scenario is expected to be worst in households that adopted both forms of coping strategies. Hence, to tackle an impending acute undernutrition, in addition to the safety net programmes to support people with short-term emergency help, nutritional counselling to combat the long-term impacts should also be considered. Such 'shock-responsive social protection' approach that links social welfare with humanitarian support by enrolling additional needy people to the already existing safety net programmes and by paying additional benefits to social welfare recipients could be a timely approach to mitigate the impending nutritional issues we are discussing here. ${ }^{42}$ Steps should also be taken to prevent any sudden spike in food prices by ensuring no prohibition to global food exports as well as uninterrupted supply of food in local markets.

While identifying the determinants of food insecurity we also have found that living in poorest households was significantly associated with mild/moderate and severe food insecurity. On the other hand, in addition to living in poorest and poorer, and even living in the richer households was significantly associated with adopting both food compromised and financial coping strategies. The phenomenon is really complex to describe. Our understanding is that richer households might have also experienced loss or decline in income as their earning sources might have also been forced to close due to the lockdown. Their income might have dropped while they continued to consume food and household resources. ${ }^{11} \mathrm{~A}$ very recent publication by Hamadani $e t a l^{28}$ also echo our findings as they reported profound impacts of COVID-19 lockdown on income and food insecurity across the population as $90 \%$ of the households they surveyed considered their financial status as unstable. ${ }^{28}$ This is also possible that richer households might have to use their financial resources to gain medical or other supports and that probably forced them to adopt different coping strategies to ensure food security at household level. We also found that the age of the respondents, the mother of the younger children of the family, had statistically significant positive association with adopting both forms of coping strategies. May be the older mothers were more experienced to try for more than one means to avert the food insecurity that their families were suffering due to the nationwide lockdown during the COVID-19 pandemic of 2020.

At the time of writing this report, the Government of Bangladesh initiated a programme for sale of essential food commodities at subsidised prices among the poorer class of people. A scheme of cash transfer was also ready for 5 million extremely poor households who would each 
receive an amount of about US\$30 transferred through mobile banking services. The above mentioned support strategies have the potential to provide food security to the households, at least for a short period of time. But, as a part of our battle against COVID-19 in the developing world where social security to every household cannot be ensured by the government system, it is critical to identify the neediest households and implement urgent long-term policies to provide economic and nutritional support to these vulnerable households in order to avoid the detrimental impacts of food insecurity. The lockdown measure is essential to contain the transmission; however following strict enforcement of a period of lockdown, limited economic activity will provide the much needed cash to the daily wage earners who are currently out of work. Allowing limited economic activity of course requires careful planning and monitoring. It is most important now to provide in a planned manner food relief to the vulnerable households.

\section{CONCLUSION}

Our findings suggest that both urban and rural poor households suffered from moderate to severe food insecurity during the month-long lockdown period in Bangladesh. But, poorest, poorer and even the richer households adopted different coping strategies that might result in long-term economic and nutritional consequences. Hence, any food relief or financial support should be allocated to the households with above mentioned characteristics first.

Acknowledgements The authors would like to thank all the participants and their parents for sharing their time and providing consent and information necessary for the successful completion of the study. The authors also acknowledge the contribution of icddr,b's core donors including Government of the People's Republic of Bangladesh, Global Affairs Canada (GAC), Canada; Swedish International Development Cooperation Agency (SIDA) and the Department for International Development, UKAid for their continuous support and commitment to the icddr,b's research efforts.

Contributors SD developed the research concept presented here. SD and TA contributed to the study design. MGR, and A-RK managed the database. SD and MAA participated in the data analysis. SD, MSH and MGR wrote the first draft. SD had primary responsibility for final content. TA and JDC critically reviewed the drafts. All authors have read and approved the final draft of the manuscript.

Funding The authors have not declared a specific grant for this research from any funding agency in the public, commercial or not-for-profit sectors.

Competing interests None declared.

Patient consent for publication Informed verbal consent was obtained from the mother or primary caregiver.

Ethics approval The study was approved by the institutional review board of International Centre for Diarrhoeal Disease Research, Bangladesh (icddr,b) and verbal informed consent was taken from the mothers/caregivers of the children before collecting the food insecurity and coping strategy data.

Provenance and peer review Not commissioned; externally peer reviewed.

Data availability statement Data are available upon reasonable request.

Supplemental material This content has been supplied by the author(s). It has not been vetted by BMJ Publishing Group Limited (BMJ) and may not have been peer-reviewed. Any opinions or recommendations discussed are solely those of the author(s) and are not endorsed by BMJ. BMJ disclaims all liability and responsibility arising from any reliance placed on the content. Where the content includes any translated material, BMJ does not warrant the accuracy and reliability of the translations (including but not limited to local regulations, clinical guidelines, terminology, drug names and drug dosages), and is not responsible for any error and/or omissions arising from translation and adaptation or otherwise.

Open access This is an open access article distributed in accordance with the Creative Commons Attribution Non Commercial (CC BY-NC 4.0) license, which permits others to distribute, remix, adapt, build upon this work non-commercially, and license their derivative works on different terms, provided the original work is properly cited, appropriate credit is given, any changes made indicated, and the use is non-commercial. See: http://creativecommons.org/licenses/by-nc/4.0/.

\section{ORCID iDs}

Subhasish Das http://orcid.org/0000-0002-7852-6569

Tahmeed Ahmed http://orcid.org/0000-0002-4607-7439

\section{REFERENCES}

1 Lu H, Stratton CW, Tang Yi-Wei. Outbreak of pneumonia of unknown etiology in Wuhan, China: the mystery and the miracle. J Med Virol 2020;92:401-2

2 Lai C-C, Shih T-P, Ko W-C, et al. Severe acute respiratory syndrome coronavirus 2 (SARS-CoV-2) and coronavirus disease-2019 (COVID-19): the epidemic and the challenges. Int J Antimicrob Agents 2020;55:105924.

3 WHO. WHO COVID-19 Dashboard: WHO, 2020. Available: https:// who.sprinklr.com

4 Balla M, Merugu GP, Patel M, et al. COVID-19, modern pandemic: a systematic review from front-line health care providers' perspective. J Clin Med Res 2020;12:215-29.

5 de Haen H, Klasen S, Qaim M. What do we really know? metrics for food insecurity and undernutrition. Food Policy 2011;36:760-9.

6 Aberman N-L, Rawat R, Drimie S, et al. Food security and nutrition interventions in response to the AIDS epidemic: assessing global action and evidence. AIDS Behav 2014;18:554-65.

7 Loopstra R. Vulnerability to food insecurity since the COVID-19 lockdown. London: The Food Foundation, 2020.

8 McCullough EB, Pingali PL, Stamoulis KG. Small farms and the transformation of food systems: an overview. Looking east looking west 2010;47:47-83.

9 Sabates-Wheeler R, Devereux S, Mitchell T. Rural disaster riskpoverty interface. Brighton: Institute of Development Studies, At the University of Sussex, 2008.

10 Harvey CA, Rakotobe ZL, Rao NS, et al. Extreme vulnerability of smallholder farmers to agricultural risks and climate change in Madagascar. Philos Trans R Soc Lond B Biol Sci 2014;369:20130089.

11 Devereux S, Béné C, Hoddinott J. Conceptualising COVID-19's impacts on household food security. Food Security 2020;12:769-72.

12 Ali D, Saha KK, Nguyen PH, et al. Household food insecurity is associated with higher child undernutrition in Bangladesh, Ethiopia, and Vietnam, but the effect is not mediated by child dietary diversity. J Nutr 2013;143:2015-21.

13 Grammatikopoulou MG, Gkiouras K, Theodoridis X, et al. Food insecurity increases the risk of malnutrition among communitydwelling older adults. Maturitas 2019;119:8-13.

14 Roetter RP, Van Keulen H. Food security. Science for agriculture and rural development in low-income countries. Berlin: Springer, 2007: 27-56.

15 Dunn CG, Kenney E, Fleischhacker SE, et al. Feeding low-income children during the Covid-19 pandemic. N Engl J Med 2020;382:e40.

16 Ehebhamen O, Obayelu A, Vaughan I, et al. Rural households' food security status and coping strategies in Edo state Nigeria. Int Food Res J 2017;24:333-40.

17 Shariff ZM, Khor GL. Household food insecurity and coping strategies in a poor rural community in Malaysia. Nutr Res Pract 2008;2:26-34.

18 Corbett J. Famine and household coping strategies. World Dev 1988;16:1099-112.

19 Hoddinott J. Shocks and their consequences across and within households in rural Zimbabwe. J Dev Stud 2006;42:301-21.

20 Devereux S. Goats before ploughs: dilemmas of household response sequencing during food shortages. IDS Bull 1993;24:52-9.

21 Chilowa W. Food insecurity and coping strategies among the low income urban households in Malawi. Bergen: Chr. Michelsen Institute. Department of Social Science And Development, 1991.

22 Ahmed T, Mahfuz M, Islam MM, et al. The MAL-ED cohort study in Mirpur, Bangladesh. Clinical Infectious Diseases 2014;59:S280-6. 
23 Alam N, Ali T, Razzaque A, et al. Health and demographic surveillance system (HDSS) in Matlab, Bangladesh. Int J Epidemiol 2017;46:809-16.

24 Coates J, Swindale A, Bilinsky P. Household food insecurity access scale (HFIAS) for measurement of food access: indicator guide: version 32007.

25 Diaz-Bonilla E, Robinson S, eds. Shaping globalization for poverty alleviation and food security, 2020 vision focus 8. Washington, DC: International Food Policy Research Institute (IFPRI), 2001.

26 Ripley B, Venables W, Ripley M. Package 'nnet'R package version, 7 2016:3-12 https://cran.r-project.org/web/packages/nnet/nnet.pdf

27 GAIN. Impact of COVID-19 on food systems: a situation report. 3 ed, 2020. https://www.gainhealth.org/resources/reports-andpublications/impact-covid-19-food-systems-situation-report-iii

28 Hamadani JD, Hasan MI, Baldi AJ, et al. Immediate impact of stayat-home orders to control COVID-19 transmission on socioeconomic conditions, food insecurity, mental health, and intimate partner violence in Bangladeshi women and their families: an interrupted time series. Lancet Glob Health 2020;8:e1380-9.

29 Raihan MJ, Farzana FD, Sultana S, et al. Effect of seasons on household food insecurity in Bangladesh. Food and Energy Security 2018;7:e00136.

30 Chowdhury M, Dibley MJ, Alam A, et al. Household food security and birth size of infants: analysis of the Bangladesh demographic and health survey 2011. Curr Dev Nutr 2018;2:nzy003.

31 Hidrobo M, Hoddinott J, Kumar N, et al. Social protection, food security, and asset formation. World Dev 2018;101:88-103.

32 Béné $\mathrm{C}$. Resilience of local food systems and links to food security - A review of some important concepts in the context of COVID-19 and other shocks. Food Secur 2020:1-18.
33 Farzana FD, Rahman AS, Sultana S, et al. Coping strategies related to food insecurity at the household level in Bangladesh. PLoS One 2017;12:e0171411.

34 FAO. Impact of COVID-19 on dhaka's food markets and food prices: situation analysis 2020 https://fscluster.org/bangladesh/document/ fao-food-market-and-food-price

35 Partners LC. Impact of coronavirus on livelihoods: low- and lower middle-income population of urban Dhaka, 2020. Available: https:// www.lightcastlebd.com/insights/2020/04/30/impact-of-coronaviruson-livelihoods-low-and-lower-middle-income-population-of-urbandhaka

36 Partners LC. Impact of coronavirus on livelihoods: rural and lowincome population of Bangladesh, 2020. Available: https://www. lightcastlebd.com/insights/2020/05/04/impact-of-coronavirus-onlivelihoods-rural-and-low-income-population-of-bangladesh

37 Solidaridad. Rapid assessment: impact of COVID-19 on agriculture \& food system in Bangladesh 2020 https://www.wur.nl/en/show/ COVID-19-Food-System-Rapid-Country-Assessment-Bangladesh. htm

38 Headey D, Heidkamp R, Osendarp S, et al. Impacts of COVID-19 on childhood malnutrition and nutrition-related mortality. The Lancet 2020;396:519-21.

39 McDonald CM, McLean J, Kroeun H, et al. Household food insecurity and dietary diversity as correlates of maternal and child undernutrition in rural Cambodia. Eur J Clin Nutr 2015;69:242-6.

40 Skalicky A, Meyers AF, Adams WG, et al. Child food insecurity and iron deficiency anemia in low-income infants and toddlers in the United States. Matern Child Health J 2006;10:177-85.

41 Ghose B, Tang S, Yaya S, et al. Association between food insecurity and anemia among women of reproductive age. PeerJ 2016;4:e1945

42 (OPM) OPM. Shock-responsive social protection systems research: literature review. Oxford: Oxford Policy Management, 2017. 